\title{
Determination of accuracy of multi implant impressions: A journey through time
}

\author{
Pragya Bali1,", Archana Nagpal², Rajeev Gupta ${ }^{3}$, Ramit Verma $^{4}$, Payal Kashyap ${ }^{5}$ \\ ${ }^{1,5}$ PG Student, ${ }^{2}$ Professor \& Head, ${ }^{3}$ Professor, ${ }^{4}$ Reader, ${ }^{1-5}$ Dept. of Prosthodontics, Himachal Dental College Sunder Nagar, \\ Himachal Pradesh, India
}

* Corresponding Author:

Email: shivangibali99@gmail.com

\begin{abstract}
Introduction: Passive fit is one of the major concerns in implant dentistry as it contributes to the long-term success of the implant treatment. Accurate implant impressions are important for the achievement of passive fit of an implant prosthesis. There is inconclusive evidence on the techniques and types of materials used for making multi-unit implant impressions .In the present article the various parameters affecting the accuracy of implant impression along with impression material and technique are reviewed.

Objective: To evaluate the scientific data related to different aspects of multi-unit implant impression accuracy and draw useful conclusions from the review for application in clinical practice.

Materials and Methods: Studies from 1990 to 2017 were evaluated. Papers examining implant impression accuracy for two or more implants were selected for review. Case reports, technique articles, and incomplete studies were excluded. Fifty-nine studies were selected for evaluation, three among them clinical and the rest in vitro.

Results: Fifteen studies compared polyvinyl siloxane (PVS) and polyether (PE) 11 found no differences between the two materials in terms of impression accuracy. Thirty studies analyzed the splint effect 13 found splinting better and 13 others elicited no differences between splinting and non-splinting. Among the 25 studies examining pickup and transfer impression techniques, 12 favored pickup over transfer and 11 found no differences between the two. Twelve studies assessed effects of various angles of implants and found significant differences in accuracy for 20 to 25degree angle and no differences for 5 to 15 -degree angle for most studies, except two.

Conclusion: PVS and PE were the preferred impression materials for multi-unit implant impressions. The evidence on splinting was inconclusive and the data supporting splint to non-splint were neutral. Pickup was the better performing technique than transfer, especially with increased number of implants. Implant angle of 20 to 25 degrees negatively affected the multi-unit implant impression accuracy.
\end{abstract}

Keywords: Accuracy, Digital impressions, Impression material, Misfit, Multi-unit implant.

\section{Introduction}

Dental Implants have brought revolutionary changes in the treatment of patients with few and completely missing teeth. Implants are different from natural teeth as osseointegrated implants have no periodontal ligament to compensate for any accuracy. Accurate multi-unit implant impression making is a challenging procedure in implant dentistry due to several reasons. It is in the best interests of the clinician to aim for a restoration with the least misfit, following the best known methods of fabrication and evaluation of the prosthesis before delivery. Though numerous research reports evaluating the factors affecting implant impression accuracy have been published in recent decades, extensive reviews on the subject have generally been rare., ${ }^{4,6}$ The latest works need close examination for assessment of their value and implications on the current clinical practice. An updated review is therefore warranted to factor in the current developments, reflect the most recent findings relevant to the topic and reconstitute the recommendations, if necessary. At present, various implant impression techniques, such as splinting of implants, pickup, and transfer techniques and different impression materials, like polyether, vinyl polysiloxane (VPS) and polysulfide have been introduced and investigated for accuracy. Other factors related to the accuracy of the implant impression, including the implant angle or depth of implants are also included. However, the results are not always consistent, and various studies reported more accuracy with different impression techniques as well as impression materials

\section{Materials and Methods}

An electronic search was performed from PubMed's data bases with key words, accuracy of implant impression techniques -invitro studies, dental reports, and review articles. The years searched were 1990 to 2017.

To select the studies, all obtained reports were reviewed. Titles and abstracts were screened for relevance. The full texts of suitable abstracts were obtained and assessed using the following inclusion and exclusion criteria.

\section{Inclusion criteria:}

1. Studies dealing with implant impression accuracy

2. Studies published since 1990 (inclusive).

Exclusion criteria

1. Case reports or technique articles

2. Only abstracts published in journals or conference proceedings 
3. Studies evaluating single-tooth implant impression accuracy

4. Review articles

\section{Results}

Most of the articles selected for analysis were invitro studies. The majority of the studies on multiunitimplant impression accuracy had been published in the last 12 years, with more than half of those papers in the last 3 years, including the three clinical studies.

Impression material: Very few studies have analyzed impression material as a factor influencing multi-unit impression precision. Most studies had utilized polyether ${ }^{14,16-18,20,46,50,54,57,65,74-76}$ (PE) impression material as a stock standard for playing out the accuracy assessment, including different factors, for example, impression system and angle of implant. Among the 17 studies $^{7-9,12,13,19,39-49}$ that studied the impression material contrasts, 15 of them looked at polyvinyl siloxane (PVS) and PE impression materials, ${ }^{7-9,12,13,39-48}$ one analyzed vinyl siloxanether (VSE) with PE,19 and another thought about PVS with irreversible hydrocolloid. ${ }^{49}$ Most of the studies ${ }^{12,13,39-48}$ have indicated similar precision, with insignificant differences among PVS and PE for multi-implant impressions, however a couple others ${ }^{7,8}$ have reported more accuracy with PVS in contrast with PE, but in some circumstances when the implants were placed subgingivally ${ }^{7}$ or were nonparallel with variable impression coping connection lengths. ${ }^{8}$ On the other hand, PE has been found to deliver better outcomes, as far as implant cast accuracy ${ }^{8}$ than VPS by a few authors. An ongoing clinical examination analyzed the new impression material VSE and observed it to be proportional or better than PE. ${ }^{19}$ Irreversible hydrocolloid with supporting was likewise tried and observed to be as exact as PVS with non-splinting in another recent investigations. ${ }^{49}$

Splinting V/s non-splinting: Among all the studies analyzing the multi-unit Implants impression accuracy, the "impacts of splinting versus non-splinting" was the most researched territory, and furthermore the generally questionable. Of the 30 studies analysed, ${ }^{10-18,46,49,50-68} 13$ supported the splinting technique, ${ }^{10,11,15,16,18,46,50-56}$ five supported non-supporting over splinting. ${ }^{58,65-68}$ and 13 found no significant difference between the supporting and non-splinting procedures with multi-unit Implants impressions. . $2-14,17,49,57-64$ In addition to the simple comparative analysis, no connection was found between the quantity of implant and the splinting strategy (splinting and nonsplint) for edentulous ridge multi-unit impression accuracy. Among studies assessing four to six implants, 11 studies $^{10,11,15,16,18,46,50,51,54-56}$ favored supporting contrasted with non-splinting and 11 demonstrated no differences ${ }^{12-14,17,49,58,60-64}$ between the two methodologies. Most investigations detailed in the writing used auto polymerizing acrylic resin as the splinting material, ordinarily in mix with dental floss. ${ }^{11,14,15,18,46,52,57-59,60,65}$ Preformed bars of auto polymerizing acrylic resin were likewise regularly utilized, related to freshly prepared self-cure resin for splinting purposes. The acrylic resin bars were segmented to proper lengths to traverse the spaces between the impression copings and after that luted to the impression copings with acrylic resin utilizing the bead brushing procedure, with the point of limiting polymerization shrinkage. ${ }^{12,13,16,17,50,52,54,80}$

One study ${ }^{80}$ compared about self-cure acrylic resin splinting and metal splinting and found that metal supporting was essentially increasingly precise for an entire curve edentulous circumstance with four implants. Another study14 compared bite registration silicone sand PE and self-cure acrylic resin splint and found no difference between the three materials. With respect to the two investigations that inspected the composite resin braces, the outcomes were blended. One examination discovered better precision with acrylic resin splints contrasted with the composite resin..$^{50}$ and another found the composite resin splint showed preferable accuracy over the non-splinting technique. ${ }^{51}$

Transfer v/s Pickup: Twenty-five studies $^{12,13,17,20,41,42,45,46,54,57,58,61,63,64,67,69-78}$ compared the accuracy among pickup and transfer impression technique. Out of the ${ }^{25,12}$ studies $^{13,17,42,46,57,58,61,63,, 67,69-72}$ inferred that pickup impressions were altogether more precise than transfer and ${ }^{11,12,20,41,45,53}$ demonstrated no significant differences between the two systems. A definite trend was observed, in that the pickup seemed to be better than transfer when there were higher number of implants involved. With regards to the use of impression copings versus abutments, with direct or indirect impressions, the results were mixed.

Digital v/s conventional impressions: Very few studies 29-31 compared digital multi-unit implant accuracy with conventional impressions. Each of the investigations differed from the other in some respect. 29, 30 and one study 31 was designed to asses completely edentulous arch. Overal, only one study 29 had favorable results with digital impressions compared to conventional, very few studies had performed digital impressions of the abutments directly on the master cast and not at the implant level.

Straight v/s angulated implants: Most examinations researching the impacts of implants angulation on the multi-unit implants impression accuracy had been performed with two implants, ${ }^{20,39,52,57,59,65,78,79}$ aside from a couple of papers which contemplated the impact with three to five implants. ${ }^{8,71,72,77}$ of the 12 thinks about dissected in this audit, one was a clinical pilot study,20 and the rest had been led in vitro. ${ }^{8,39,52,57,59,65,71,72,77,78,79}$

Three studies explored the impacts of 25-degree angulation $^{39,52,65}$ and one investigation up to 20 degrees, ${ }^{79}$ and all discovered significant difference in accuracy between experimental casts and master casts. 
Splinted direct technique was observed to be the most exact for multi-unit situation with two exceptionally unparallel (20-to 25-degree difference) implants. ${ }^{39,52}$ Ten studies ${ }^{8,20,39,57,59,71,72,77-79}$ evaluated the impact of 5to 15-degree implants disparity. All examinations, aside from two, found no critical contrasts in accuracy up to angulations of 15 degrees compared with parallel implants. The two studies that were compared at 10 and 15 degrees divergence ${ }^{8,72}$ had been intended to survey four to five implants, though all others that evoked no distinctions had either assessed with two $0^{20,39,57,59,78,79}$ or three ${ }^{71,77}$ implants. Consequently a connection was seen between increased number of implants and impression incorrectness notwithstanding for minor angulations.

Other factors influencing accuracy: Regarding the tray type and material, rigid custom trays ${ }^{81}$ or modified metal stock trays ${ }^{82}$ produced more precise impressions in examination with the polycarbonate (plastic) stock trays. On the reuse of impression copings, it has been demonstrated that the impression accuracy is unaffected when copings were reused up to ten times. ${ }^{83}$

\section{Discussion}

The present survey paper chose and broke down the important logical works researching the clinical variables influencing multi-unitimplants impression accuracy.

The greater part of the surveyed examinations were in vitro and for the most part inspected four clinical variables influencing insert impression making, to be specific impression material, splinting or without splinting, impression system (open tray or closed tray), and angles of implants. On examination of the information, an ongoing increment in the production of articles identified with implants impression precision was noted. The finding might be characteristic of the way that there is extraordinary enthusiasm for this zone of research, and, moreover, with the appearance of new impression systems and materials, more in vitro and clinical investigations are being directed.

Impression materials: PVS and PE keep on being the impression materials of decision, in spite of the fact that $\mathrm{PE}$ has been the favored material with numerous creators, particularly those surveying multiunit implants impression precision in edentulous ridges..$^{10,11,14,16-}$ $18,46,50,54,7$

Splint V/s non-splint: In the present paper, there were no distinctions found among splinting and nonsplinting, based on the number of studies that examined the effect and supporting either technique. The present evidence on implants impression precision with splinting is mostly founded on auto polymerizing resin as a splinting material used in various ways. ${ }^{11-}$ $18,46,52,54,57-59,60,65,80$ The other materials such as composite resins. ${ }^{50,51}$ bite-registration silicones and $\mathrm{PEs}^{14}$ have just been utilized as of late to support, in multiple implant impressions. In the limited studies performed with these materials. ${ }^{14,50}$ the results have been found to be promising. More research is required to substantiate use of these materials on a regular basis. Preformed acrylic resin bars connected to the copings using acrylic resin with or without sectioning and rejoining has been increasingly employed as the preferred splinting technique by many authors in the recent literature. . $^{12,13,16,17,50,52,54,80}$ Studies comparing different splinting techniques and materials in terms of impression accuracy are few in number ${ }^{14,50,51,80}$ and more studies are required in the area.

Pickup V/s Transfer: Overall, evaluating the entire data, it seemed that no technique had a distinct advantage over the other, although pickup was the preferred technique with greater number of implants. ${ }^{12,13,16,17,50,52,54,80}$ These studies evaluated abutment level impressions with plastic coping cylinder. Technically, the impressions were pickups as the components were transferred into the set material of the impressions; however as these were performed with a closed tray that still required abutments to be transferred and repositioned into the plastic copings without direct contact with the impression material, they were considered and analyzed as indirect or closed tray techniques in this review.

Digital v/s conventional impressions: The scientific research on the joined utilization of digital impressions with CAD/CAM (computer aided design/computerassisted manufacture) techniques for the manufacture of multi-unit implant restoration is at a fundamental stage. Very few studies have been accounted for on the utilization of intra oral scanners and laboratory scanners to record 3D dental implant positions utilizing filter bodies or potentially computerized coded abutments. More in-vitro and clinical investigations require to be performed looking at the accuracy of intra oral advanced impressions versus ordinary impressions.

Implant angulation: The majority of the studies assessing the impacts of implant angulation had done as such with two implants, ${ }^{20,39,52,57,59,65,78,79}$ with only three investigations researching the impact on three to five implants. ${ }^{71,72,77}$ More research is required with expanded quantities of implants to loan further clearness to the subject. Evidence has shown that the length of the connection part of the impression coping in internal connection implants could influence the accuracy of the multi-unit implants level impression ${ }^{8}$ as the shortened length offsets the higher removal stress induced by the implant divergence. This possible phenomenon needs to be thoroughly assessed.

The implants angulations can be further managed through the use of multi-base abutments and abutment level impressions with impression copings. ${ }^{12,20,78}$ the advantage is that the abutments aid in eliminating the increased contact area between the impression copings and the internal connection implants, which in turn reduced the deformation of the impression material and movement of the copings during removal and transfer. 


\section{Conclusion}

Within the limitations of this study, the conclusions

based on the literature review are:

1. PVS and PE appear to be the impression materials of choice for multi-unit implants impressions.

2. Pickup impression technique is possibly superior to the exchange procedure for delivering precise impressions, particularly with increased number of implants.

3. Splinting of impression copings did not appear to influence the accuracy of the multi-unit implants impressions.

\section{References}

1. Jemt T, Prosthesis misfit and marginal bone loss in edentulous patients. Int J Oral Maxillofac Implants. 1996;11:620-25.

2. Sahin S, Çehreli MC. The significance of passive framework fit in implant prosthodontics: current status. Implant Dent. 2001;10:85-92.

3. Kan JYK, Rungcharassaeng K, Bohsali K, Goodacre CJ, Lang BR. Clinical methods for evaluating implant framework fit. J Prosthet Dent. 1999;81:7-13.

4. Lee H, So JS, Hochstedler JL, Ercoli C. The accuracy of implant impressions: a systematic review. J Prosthet Dent. 2008;100:285-91.

5. Gracis S, Michalakis K, Vigolo P, von Steyern PV, Zwahlen M, Sailer I. Internal v/s external connections for abutments/reconstructions: a systematic review. Clin Oral Implants Res. 2012;23(6):202-16.

6. Chee W, Jivraj S. Impression techniques for implant dentistry. Dr Dent J. 2006;201:429-32.

7. Lee H, Ercoli C, Funkenbusch PD, Feng C. effect of subgingival depth of implant placement on the dimensional accuracy of the implant impression: an in vitro study. J Prosthet Dent. 2008;99:107-13.

8. Sorrentino R, Gherlone EF, Calesini G, Zarone F. Effect of implant angulation,connection length, and impression material on the dimensional accuracy of implant impressions: an in-vitro comparative study. Clin Implant Dent Relat Res. 2010;12:63-76.

9. Del'Acqua MA, Chavez AM, Amaral AL, Compagnoni MA, Mollo Jr D. Comparison of impression techniques and materials for an implant-supported prosthesis. Int $J$ Oral Maxillofac Implants. 2010;25:771-76.

10. Naconecy MM, Teixeira ER, Shinkai RSA, Frasca LC, Cervieri A. Evaluation of the accuracy of 3 transfer techniques for implant-supported prostheses with multiple abutments. Int J Oral Maxillofac Implants. 2004;19:192-98.

11. Al-Quran FA, Rashdan BA, Abu Zomar AA, Weiner S. Passive fit and accuracy of three dental implant impression techniques. Quintessence Int. 2012;43:11925.

12. Chang W, Vahidi F, Bae K, Lim B. Accuracy of three implant impression techniques with impression materials and stones. Int J Prosthodont. 2012;25:44-47.

13. Mostafa TM, Elgendy MN, Kashef NA, Halim MM. Evaluation of the precision of three implant transfer impression techniques using two elastomeric impression materials. Int J Prosthodont. 2010;23:525-28.

14. Hariharan R, Shanker C, Rajan M, Baig MR, Azhagarasan NS. Evaluation of accuracy of multiple dental implant impressions using various splinting materials. Int J Oral Maxillofac Implants. 2010;25:38-44.
15. De Faria J, Silva-Concilio LR, Neves AC, Miranda ME, Teixeira ML. Evaluation of accuracy of different transfer impression techniques for multiple implants. $\mathrm{Braz}$ Oral Res 2011;25:163-67.

16. Vigolo P, Fonzi F, Majzoub Z, Cordioli G. An evaluation of impression techniques for multiple internal connection implant prostheses. J Prosthet Dent. 2004;92:470-76.

17. Stimmelmayr M, Erdelt K, Guth J, Happe A, Beuer F. Evaluation of impression accuracy for a four-implant mandibular model: a digital approach. Clin OralInvesting. 2012;16:1137-142.

18. Lal K, White GS, Weber H, Galluci GO. Accuracy of splinted and non-splinted impression techniques on the accuracy of fit of fixed implant prostheses in edentulous patients: a comparative study. Int. J Oral Maxillofac Implants. 2011;26;1267-72.

19. Enkling N, Bayer S, Johren P, Mericske-Stern R. Vinyl siloxanether: a new impression material. Clinical study of implant impressions with vinyl siloxan ether v/s poly ether materials. Clin Implant Dent Relat Res. 2012;14:144-51.

20. Gallucci GO, Papaspyridakos P, Ashy LM, Kim GE, Brady NJ, Weber H. Clinical accuracy outcome of closed tray and open tray implant impression techniques for partially edentulous patients. Int J Prosthodont. 2011;24:469-72.

21. Abduo J, Bennani V, Waddell N, Lyons K, Swain M. Assessing the fit of implant fixed prostheses: a critical review. Int J Oral Maxillofac Implants. 2010;25:506-15.

22. Karl M, Graef F, Heckmann SM, Taylor T. A methodology to study the effects of prosthesis misfit over time: An in vivo model. Int J Oral Maxillofac Implants. 2009;24:689-94.

23. Phillips KM, Nicholls JI, Ma T, Rubenstein J. The accuracy of three implant impression techniques: a threedimensional analysis. Int J Oral Maxillofac Implants. 1994;9:533-40.

24. Ma T, Nicholls JI, Rubenstein JE. Tolerance measurements of various implant components. Int J Oral Maxillofac Implants. 1997;12:371-75.

25. Jemt T. Failures and complications in 391 consecutively inserted fixed prostheses supported by Brånemark implant in the edentulous jaw: a study of treatment from the time of prostheses placement to the first annual check up. Int J Oral Maxillofac Implants. 1991;6:270-76.

26. Papaspyridakos P, Benic GI, Hogsett VL, White GS, Lal K, Galluci GO. Accuracy of implant casts generated from splinting and non-splinting impression techniques for edentulous patients: an optical scanning study. Clin Ora lImplants Res. 2012;23;676-81.

27. Jemt $\mathrm{T}$, Prosthesis misfit and marginal bone loss in edentulous patients. Int J Oral Maxillofac Implants. 1996;11:620-25.

28. Wee AG, Aquilino SA, Schneider RL. Strategies to achieve fit in implant prosthodontics: a review of literature. Int J Prosthodont. 1999;12:167-78.

29. Karl M, Graef F, Schubinski P, Taylor T. Effect of intraoral scanning on the passivity of fit of implant-supported fixed dental prostheses. Quintessence Int. 2012;43:55562.

30. Eliasson A, Ortorp A. The accuracy of an implant impression technique usingdigitally coded healing abutments. Clin Implant Dent Relat Res. 2012;14(1):3038.

31. Stimmelmayr M, Guth J, Erdelt K, Edelhoff D, Beuer F. Digital evaluation of the reproducibility of implant scan body fit: an in vitro study. Clin Oral Investing. 2012;16:851-56. 
32. Daoudi MF, Setchell DJ, Searson LJ. A laboratory investigation of the accuracy of two impression techniques for single-tooth implants. Int J Prosthodont. 2001;14:152-58

33. Lee SJ, Gallucci GO. Digital v/s conventional implant impressions: efficient outcomes. Clin Oral Implants Res. 2013;24:111-115.

34. Ramsey CD, Ritter RG. Utilization of digital technologies for fabrication of definitive implant-supported restorations. J Esthet Restor Dent. 2012;24:299-99.

35. Linkevicius T, Svediene O, Vindasiute E, Puisys A, Linkeviciene L. The influence of implant placement depth and impression material on the stability of an open tray impression coping. J Prosthet Dent. 2012;108:23843.

36. Vigolo P, Majzoub Z, Cordioli G. Master cast accuracy in single tooth implant replacement cases: an in vitro comparison. A technical note. Int J Oral Maxillofac Implants 2005;20:455-460.

37. Daoudi MF, Setchell DJ, Searson LJ. An evaluation of three implant leve limpression techniques for single tooth implant. Eur J Proshthodont Restor Dent 2004;12:9-14.

38. Vigolo P, Majzoub Z, Cordioli G. In vitro comparison of master cast accuracy for single tooth implant replacement. J Prosthet Dent 2000;83:562-566.

39. Rutkunas V, Sveigata K, Savickas R. Effects of implant angulation, material lselection, and impression technique on impression accuracy: a preliminary laboratory study. Int J Prosthodont 2012;25:512-515.

40. Aguilar ML, Elias A, Vizcarrondo C, Psoter WJ. Analysis of three-dimensional distortion of two impression materials in the transfer of dental implants. J Prosthet Dent 2009;101:202-209.

41. Wenz HJ, Hertrampf K. Accuracy of impressions and casts using differen timplant impression techniques in a multi-implant system with an internal hex connection. Int J Oral Maxillofac Implants 2008;23:39-47.

42. Wostmann B, Rehmann P, Balkenhol M. Influence of impression technique and material on the accuracy of multiple implant impressions. Int. J

Prosthodont2008;21:299-301.

43. Holst S, Blatz MB, Bergler M, Goellner M, Wichmann M. Influence of impression material and time on the 3dimensional accuracy of implant impressions. Quintessence Int 2007;38:67-73.

44. Cehreli MC, Akça K. Impression techniques and misfitinduced strains on implant-supported superstructures: an in vitro study. Int J Periodontics Restorative Dent. 2006;26:379-85.

45. Akça K, Cehreli MC. Accuracy of 2 impression techniques for ITI implants. Int J Oral Maxillofac Implants. 2004;19:517-523.

46. Assuncao WG, Filho HG, Zaniquelli O. Evaluation of transfer impressions for osseointegrated implants at various angulations. Implant Dent. 2004;13:358-366.

47. Wee AG. Comparison of impression materials for direct multi-implant impressions. J Prosthet Dent. 2000;83:323-31.

48. Lorenzoni M, Pertl C, Penkner K, Polansky R, Sedaj B, Wegscheider WA. Comparison of the transfer precision of three different impression materials in combination with transfer caps for the Frialit-2 system. J Oral Rehabil. 2000;27:629-38.

49. Ferreira VF, Barboza EP, Gouvea CV, Bianchini GM, Mussallem F, Carvalho WR. Comparative study of the polyvinyl siloxane technique with resin-splinted transfer copings used for multiple implant abutment impressions. Implant Dent. 2012;21:72-76.
50. Ongul D, Gokcen-Rohlig B, Sermet B, Keskin H. A comparative analysis of the accuracy of different direct impression techniques for multiple implants. Aust Dent $J$. 2012;57:184-89.

51. Del'Acqua MA, Chavez AM, Compagnoni MA, MolloJr D. Accuracy of impression techniques for an implantsupported prosthesis. Int J Oral MaxillofacImplants. 2010;25:715-21.

52. Filho HG, Mazaro J, Vedovatto, E, Assuncao W, Santos P. Accuracy of impression techniques for implants. Part 2: Comparison of splinting techniques. J Prosthodontics. 2009;18:172-76.

53. Cabral LM, Guedes CG. Comparative analysis of 4 impression techniques for implants. Implant Dent. 2007;16:187-194.

54. Vigolo P, Majzoub Z, Cordioli G. Evaluation of the accuracy of three techniques used for multiple implant abutment impressions. J Prosthet Dent. 2003;89:186192.

55. Assif D, Marshak B, Schmidt A. Accuracy of implant impression techniques. Int J Oral Maxillofac Implants. 1996;11:216-22.

56. Assif D, Fenton A, Zarb G, Schmitt A. Comparative accuracy of implant impression procedures. Int $J$ Periodontics Restorative Dent. 1992;12:112-21.

57. Lee Y, Heo S, Koak J, Kim S. Accuracy of different impression techniques for internal connection implants. Int J Oral Maxillofac Implants. 2009;24:823-30.

58. Del'Acqua MA, Filho J, Compagnoni MA, MolloJr D. Accuracy of impression and pouring techniques for an implant-supported prosthesis. Int J Oral MaxillofacImplants. 2008;23:226-36.

59. Choi JH, Lim YJ, Yim S, Kim CW. Evaluation of the accuracy of implant-level impression techniques for internal-connection implant prostheses in parallel and divergent models. Int J Oral Maxillofac Implants. 2007;22:761-68.

60. Kim S, Nicholls JI, Han CH, Lee KW. Displacement of implant components from impressions to definitive casts. Int J Oral Maxillofac Implants 2006;21:747-55.

61. Herbst D, Nel JC, Driessen CH, Becker PJ. Evaluation of impression accuracy for osseointegrated implant supported superstructures. J Prosthet Dent. 2000;83:55561.

62. Hsu CC, Millstein PL, Stein RS. A comparative analysis of the accuracy of implant transfer techniques. J Prosthet Dent. 1993;69:588-93.

63. Barrett MG, Rijk WG, Burgess JO. The accuracy of six impression techniques for osseointegrated implants. $J$ Prosthodont. 1993;2:75-82.

64. Humphries RM, Yaman P, Bloem TJ. The accuracy of implant master casts constructed from transfer impressions. Int J Oral Maxillofac Implants. 1990;5:33136.

65. Assuncao WG, Cardoso A, Gomes EA, Tabata LF, Santos PH. Accuracy of impression techniques for implants. Part 1: Influence of transfer copings surfaceabrasion. J Prosthodont. 2008;17:641-47.

66. Burawi G, Houston F, Byrne D, Claffey N. A comparison of the dimensional accuracy of the splinted and unsplinted impression techniques for the Bone-Lock implant system. J Prosthet Dent. 1997;77:68-75.

67. Phillips KM, Nicholls JI, Ma T, Rubenstein J. The accuracy of three implant impression techniques: a threedimensional analysis. Int J Oral Maxillofac Implants. 1994;9:533-40.

68. Inturregui JA, Aquilino SA, Ryther JS, Lund PS. Evaluation of three impression techniques for 
osseointegrated oral implants. J Prosthet Dent. 1993;69:503-509.

69. Tarib NA, Seong TW, Chuen KM, Kun MS, Ahmad M, Kamarudin KH. Evaluation of splinting implant impression techniques: two dimensional analyses. Eur $J$ Prosthodont Restor Dent. 2012;20:35-39.

70. Kwon J, Son Y, Han C, Kim S. Accuracy of implant impressions without impression copings: a threedimensional analysis. J Prosthet Dent. 2011;105:367-73.

71. Jo S, Kim K, Seo J, Song K, Park J. Effect of impression coping and implant angulation on the accuracy of implant impressions: an in-vitro study. $J$ Adv Prosthodont. 2010;2:128-33.

72. Carr AB. Comparison of impression techniques for a five-implant mandibular model. Int J Oral Maxillofac Implants. 1991;6:448-55.

73. De La Cruz JE, Funkenbusch PD, Ercoli C, Moss ME, Graser GN, Tallents RH. Verification jig for implantsupported prostheses: a comparison of standard impressions with verification jigs made of different materials. J Prosthet Dent. 2002;88: 329-36.

74. Rashidan N, Alikhasi M, Samadizadeh S, Beyabenaki E, Kharazifard MJ. Accuracy of implant impressions with different impression coping types and shapes. Clin Implant Dent Res. 2012;14:218-25.

75. Alikhasi M, Siadat H, Monzavi A, Momen-Heravi H Three dimensional accuracy of implant and abutment level impression techniques: effect on marginal discrepancy. J Oral Implantol. 2011;37:649-57.

76. Walker M, Ries D, Borrelo B. Implant cast accuracy as a function of impression techniques and impression material viscosity. Int J Oral Maxillofac Implants. 2008;23:669-74.

77. Conrad HJ, Pesun IJ, DeLong R, Hodges JS. Accuracy of two impression techniques with angulated implants. $J$ Prosthet Dent. 2007;97:349-56.

78. Carr AB. Comparison of impression techniques for a twoimplant 15-degree divergent model. Int J Oral Maxillofac Implants. 1992;7:468-75.

79. Jang HK, Kim S, Shim JS, Lee KW, Moon HS. Accuracy of impressions for internal-connection implant prostheses with various divergent angles. Int J Oral Maxillofac Implants 2011;26:1011-1015.

80. Del Aqua M, Chavez A, Castanharo S, Compagnoni M, MolloJr F. Effect of splint material rigidity in implant impression techniques. Int J Oral Maxillofac Implants 2010;25:1153-58.

81. Burns J, Palmer R, Howe L, Wilson R. Accuracy of open tray implant impressions:an in vitro comparison of stock versus custom trays. J Prosthet Dent. 2003;89:250-55.

82. Del Aqua M, de Avila E, Amaral A, Pinelli L, MolloJr F. Comparison of the accuracy of plastic and metal stock trays for implant impressions. J Oral Maxillofac Implants. 2012;27:544-50.

83. Alikhasi M, Bassir S, Naini R. Effect of multiple use of impression copings on the accuracy of implant transfer. Int J Oral Maxillofac Implants. 2013;28:408-14.View publication

84. Selvaraj S, Dorairaj J, Mohan J, Simor P. Comparison of implant accuracy of multiple implant impression technique with different splinting materials: An in vitro study. J of Indian Prosthodontic Society 2016;16.

How to cite the article: Bali $P$, Nagpal A, Gupta R, Verma R, Kashyap P. Determination of accuracy of multi implant impressions: A journey through time. Ann Prosthodont Restor Dent. 2018;4(4):105-110. 